\title{
PROJECT QUALITY ANALYSIS AND MEASUREMENT OF UNDERGRADUATE LEVEL: PROJECT QUALITY ASSESSMENT METHODOLOGY (PQAM) MODEL
}

\author{
Mohammad Rashid Hussain ${ }^{1}$, Usman Ahmed ${ }^{2}$, Mohammad Ashiquee Rasool ${ }^{3}$ \\ ${ }^{\text {I} A s s i s t a n t ~ P r o f e s s o r, ~ D e p a r t m e n t ~ o f ~ I n f o r m a t i o n ~ S y s t e m s, ~ C o l l e g e ~ o f ~ C o m p u t e r ~ S c i e n c e, ~ K i n g ~ K h a l i d ~ U n i v e r s i t y, ~}$ \\ Abha, Kingdom of Saudi Arabia \\ ${ }^{2}$ Assistant Professor, Department of Information Systems, College of Computer Science, King Khalid University, \\ Abha, Kingdom of Saudi Arabia \\ ${ }^{3}$ Lecturer, Department of Information Systems, College of Computer Science, King Khalid University, Abha, Kingdom \\ of Saudi Arabia
}

\begin{abstract}
This document introduce one of the best Project Quality Assessment Methodology (PQAM) Model for undergraduate level education to develop the quality of Project by comparing them according to 8 criteria's and their respective sub criteria's through the effective mathematical recommended technique to evaluate the weightage of individual one. The effectiveness of success measures was identified for their level of success criticality to the Undergraduate projects. Some of the Academic Project quality improvement in undergraduate level education has recently been considered in many universities over the world, based on some existing methodology, PQAM model have been developed and implemented in some Universities and Colleges to evaluate the performance and contribution of individual one in their respective group. The effectiveness of success measures was identified for their level of success criticality to the Undergraduate projects, a concept have been introduced to investigate method to sort out the existing issues of the project quality and performance evaluation of undergraduate level education. Results were collected in the form of passive observation i.e. regular observation through the Project supervisor by the process of questionnaire to find out the reflections of individual one and provide a different task to individual one for self-assessments and group-evaluations and also use a log-table for future reference.
\end{abstract}

Keywords:- Project Quality Assessment methodology; Self-Assessment; Group-Evaluation; individual- weightage; level of success; Regular-Observation; log-table.

\section{INTRODUCTION}

Project Quality Assessment Methodology (PQAM) can provide an effective methodology for Examiners to evaluate the performance of individual ones based on criteria's and their respective sub criteria's, while observing the project assessment process, initially there was few scales to identify the performance and it was not enough to justify individual one and it is also not justified that to assign a same grade to every members of their respective groups, it cause a demotivation for deserving candidates, as they were aware that some of the members are simply getting the same grade like deserving one, only by standing as a group members. Based on introduced methodology weight of complete marks have been divided on some criteria to judge the individual performance and award the marks on respective scales. This methodology will improve the contribution of every one to work with dedication to achieve a good marks as per there contribution over the project and as well as the quality of project will also improve.

The term "collaborative learning" is the process of learning in a small groups to get a specific goal with the help of every members of their respective groups, but it is not possible to get an equal contribution from every one, various performance levels work together and it increase interest among them and improves their performance in creativity and promote their way of thought to solve problems, and make decisions as a team that develop and enhance the way of thought, now a days the technology is one of the challenges to adopt and use to move parallel with adopted one and collaborative learning improve and help to become a part of achievement. According to Slavin for effective collaborative learning, there must be "group goals" and "individual accountability". When the group's task is to ensure that every group member has learned something, it is in the interest of every group member to spend time explaining concepts to group mates. One of the best example of collaborative work, when I was in Engineering third year, I discussed with my classmates to start preparation of GATE exam for going to higher education and we four candidates of same discipline were decided to prepare together, In a room we arranged our table separately in front of four walls to keep our selected material, books and notes separately and at the end of every day of preparation, before going to bed we discuss 1 to 2 hours over the same decided topic to study on the day and result of the collaborative learning we all got 
a good percentile and went for higher education. Collaborative Learning is an effective learning technique towards the common academic goal that involves a critical thinking i.e. analysis, synthesis, and evaluation of the concepts, Grading Procedure Research has consistently found that students who gain most from cooperative work are those who give and receive elaborated explanations. Therefore, this study incorporated both "group goals" and "individual accountability. Bruner contends that collaborative and cooperative learning methods improve problem- solving strategies. According to Vygotsky students are capable of performing at higher intellectual levels when asked to work in collaborative situations than when asked to work individually.

The ideas of collaborative learning have been introduced in proposed methodology PQAM Model to encourage students to improve and develop their critical thinking through discussion, clarification of ideas, and evaluation of others' ideas. Therefore, if the purpose of instruction is to enhance critical- thinking and problem- solving skills, then collaborative learning is more beneficial.

According to Dr Kate Exley [3] Senior Academic Staff Development Officer, University of Leeds and Independent Consultant in Higher Education Development 'Managing and Assessing Students Working in Groups' Developing effective group working abilities at university is a positive and valuable addition to a student's skills set but Assessing 'products' too has its difficulties. The biggest decision is should all members of a student team be awarded the same mark? Such an approach really does value the collaborative effort as a whole and more closely models 'real life' but it can lead to students' disaffection when they feel their peers haven't contributed equally. Alternatively, teachers can explore ways of recognizing the different abilities and contributions made by the individual students and grade accordingly.

There are different criteria's for the assessment of group work, first the supervisor will award the grade, based on their regular performance and based on different modules assigned to the members of specific group, this methodology justify the individual works and favor those students who have given more effort over the project and reached up to the destination i.e. the goal of the project.

\section{This Study Asks}

How to allocate a grade to individual one in collaborative works of a group?

What strategies teacher will use to justify the grade of students, either based on individual performance and contribution in a group or some other strategies will be used?

\section{RELATED WORK}

The Concept of group work, it should be collaborative, supportive, contributive and cooperative in between every members of their respective group work project, Parallel contribution and discussion in between every members of a specific group i.e. collaborative and co-operative learning have been researched and achieved a positive effects in respect of increasing work efficiency and there way of thought to achieve their goals. Simon Williams 2016 Investigating the allocation and corroboration of individual grades for project-based learning[1], F. Javier Murillo 2017, Students' conceptions about a fair assessment of their learning [2], Bryan W. Griffin 2016, Perceived autonomy support, intrinsic motivation, and student ratings of instruction [4], Ian Jones 2015, Peer assessment using comparative and absolute judgement [6], Stavroula Valiandes 2015, Evaluating the impact of differentiated instruction on literacy and reading in mixed ability classrooms: Quality and equity dimensions of education effectiveness [7], Heidi Hyytinen 2015, Problems tising the equivalence of the test results of performance-based critical thinking tests for undergraduate students [8], Antonella Certa 2015, A multi-criteria approach for the group assessment of an academic course: A case study [9], Robbert Smit 2014, Assuring the quality of standards-oriented classroom assessment with rubrics for complex competencies [11]

\subsection{Collaborative Assessment}

Collaborative assessment have been investigated from different studies, Simon Williams 2016 [1] and F. Javier Murillo 2017 [2] an Investigating the allocation and corroboration of individual grades for project-based learning, 'Self-Assessment Rubrics to assess process' the process to evaluate their grades, either very good, good or developing have been decided based on Research and collecting information, Sharing their ideas with all members of their respective groups members, completing their task as per given deadline or not, contribution of their ideas with every members, Listening to other group members i.e. their ideas and suggestion and how everyone is cooperative to each other. Students' conceptions about a fair assessment of their learning introduced two main conceptions about 'what is a fair assessment' 1. Egalitarian fair assessment and 2. Equitable fair assessment by Bryan W. Griffin 2016 [4] and Ian Jones 2015 [6]; Perceived autonomy support, intrinsic motivation, and student ratings of instruction have been decided based on Summary of Outcome and Predictor Variables based on Variable Scale Range 1 to 5 (1 "Poor" to 5 "Excellent) and Peer assessment using comparative and absolute judgment, the concept have been introduced based on two arguments, 1. Comparative judgment approach and 2. An alternative technique based on absolute judgment yielded poor reliability and validity. This paper conclude that sound outcomes are achievable without assessment criteria, but success depends on how the peer assessment activity is designed.

1. Evaluating the impact of differentiated instruction on literacy and reading in mixed ability classrooms: Quality and equity dimensions of education effectiveness, performance 
of candidates have been measured based on Fit indices (Rasch model) for initial and final observations using the differentiated teaching observation protocol i.e. parameter with their respective parameters in respect of initial measurement and final measurement (Parameters are Mean, Standard deviation, Reliability, Mean infit mean square, Mean outfit mean square, Infit $t$ and Outfit $t$, Teachers have been considered a criteria's for each parameters and their respective initial and final measurement have been found by Stavroula Valiandes 2015 [7] and Heidi Hyytinen 2015 [8], Problematizing the equivalence of the test results of performance-based critical thinking tests for undergraduate students i.e. the qualitative analysis of Collegiate Learning Assessment (CLA) responses was divided into several phases and Coding focused on the following qualities of critical thinking, (1) Identifying, interpreting, synthesizing information from multiple sources to reach a conclusion; (2) evaluating the acceptability of information; and (3) producing explanations and arguments. Thoroughly processing students seemed to be able to create their responses by evaluating and analyzing the different points of views rather than just selecting the most plausible answer.

2. A multi-criteria approach for the group assessment of an academic course: A case study i.e. Assessment of efficacy of the academic course have been divided in some modules (Module 1: Safety and ergonomic, Module 2: Risk analysis, Module 3: Fire prevention, Module 4: Construction site, Module 5: Management systems and risk management for the safety and Semantic judgment have been scaled with numerical values. Actually, the aim of the analysis is to investigate both the individual assessments of the undergraduate students and aggregate the assessments with relation to the different training course goals, Antonella Certa 2015 [10] and Robbert Smit 2014 [11] are assuring the quality of standards-oriented classroom assessment with rubrics for complex competencies i.e. the framework and the relations between standards, tasks and rubrics, tasks offer the opportunity to learn in a certain area of competence and rubrics specify the requirements in a certain area of competence and a group of related tasks.

\subsection{Data Collection}

There are different assessment criteria's have been introduced for the supervisor and examiners to award the marks to individual one based on their respective performance in different criteria's, Supervisor can write notes on the behavior and interactions of the research participants and scale their marks on regular basis of selfassessments, group-evaluations and wiki logs these methodology improves their individual performance because The term "collaborative learning" refers to an instruction methodology in which students at various performance levels work together in small groups toward a common goal. The students are responsible for one another's learning as well as their own. Thus, the success of one student helps other students to be successful "Collaborative Learning Enhances Critical Thinking”.

Data for this study were collected from passive observation by using Performance measurement codes with criteria's and their respective weights.

\subsection{Research Design}

For research design it has been decided to answer the research questions are Investigating the allocation and corroboration of individual grades for project-based learning by Simon Williams [1] is a best suited example of Project Quality Assessment Methodology (PQAM) Model with different criteria's that have been introduced in this research paper.

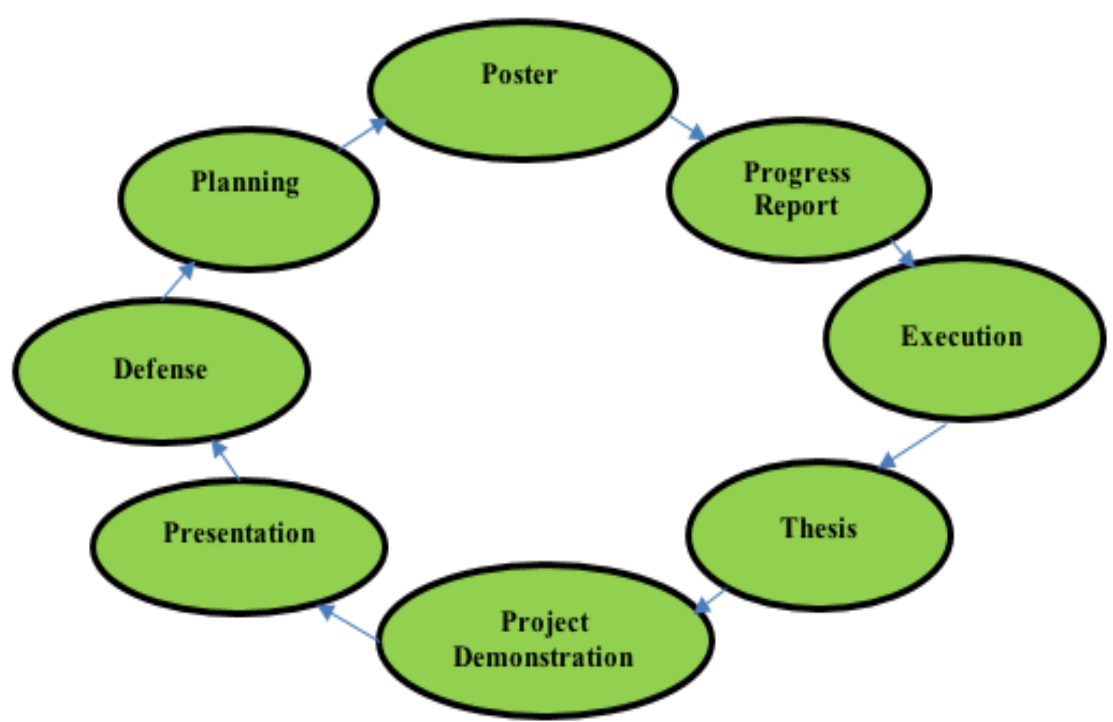

Fig 1: Assessment Framework for Overall Assessment methodology based on PQAM Model 


\subsection{Codes}

Table 1: Assessment criteria and sub criteria with their respective numeric weights

\begin{tabular}{|c|c|c|c|}
\hline Criteria & Sub criteria & $\begin{array}{l}\text { Weight }(\Phi j, \\
i=1,2,3,4)\end{array}$ & $\begin{array}{l}\text { Weight Code }(W i, \\
i=1 \text { to } 14)\end{array}$ \\
\hline Planning $(\mathrm{P})$ & Project Plan and Team Roles & $\Phi 1$ & W1 \\
\hline \multirow{2}{*}{$\operatorname{Poster}\left(\mathrm{P}_{\mathrm{o}}\right)$} & Preparation & $\Phi 1$ & $w_{2}$ \\
\hline & Presentation and defense & $\Phi 1$ & w3 \\
\hline Progress Report(Rp) & Presentation and structure & $\Phi 1$ & W4 \\
\hline \multirow{4}{*}{ Execution $\left(\mathrm{E}_{\mathrm{x}}\right)$} & Initiative & $\Phi 1$ & W5 \\
\hline & Logbook & $\Phi 1$ & W6 \\
\hline & Attendance at both Lectures and Weekly meetings & $\Phi 1$ & W7 \\
\hline & Attitude & $\$ 1$ & WB \\
\hline \multirow{3}{*}{ Thesis $\left(\mathrm{T}_{\mathrm{h}}\right)$} & Work (originality, breadth and depth) & $\Phi 2$ & w9 \\
\hline & Presentation and Structure & $\Phi 4$ & W10 \\
\hline & Clarity & $\Phi 2$ & W11 \\
\hline Project Demonstration $\left(\mathrm{P}_{\mathrm{d}}\right)$ & Quality and explanation of project software & $\Phi 3$ & W12 \\
\hline Presentation $\left(\mathrm{P}_{\mathrm{r}}\right)$ & Contents, Structure, Clarity, Use of slides, Flow, Timing, Delivery & $\$ 3$ & W13 \\
\hline Defense $\left(D_{f}\right)$ & Breadth and Depth of Knowledge (theoretical and practical) & \$3 & W14 \\
\hline
\end{tabular}

$\Phi 1=0.5, \Phi 2=0.75$ and $\Phi 3=1.0, \Phi 4=1.5$

(1) Here, equation (1) the weights of sub criteria's of 'table 1' have been introduced for the examiners to award these to individual one in a group in respect of their performance in each criteria's.

Table 2: Performance level awarded by supervisor

\begin{tabular}{|l|l|l|l|l|}
\hline Performance Level $\left(\mathbf{P}_{\mathbf{l}}\right)$ & $\begin{array}{l}\text { Satisfactory -Good } \\
(\mathbf{6 . 0 0 - 6 . 9 9 )}\end{array}$ & $\begin{array}{l}\text { Good - } \\
\text { V. Good } \\
\mathbf{( 7 . 0 0 - 7 . 9 9 )}\end{array}$ & $\begin{array}{l}\text { V. Good- } \\
\text { Excellent } \\
\mathbf{( 8 - 8 . 9 9 )}\end{array}$ & $\begin{array}{l}\text { Excellent -Outstanding } \\
\mathbf{( 9 . 0 0 - 9 . 9 9 )}\end{array}$ \\
\hline Numeric value $(\mathbf{N v})$ & $\delta=6, \delta+=6.99$ & $\gamma=7, \gamma+=7.99$ & $\beta=8, \quad \beta+=8.99$ & $\alpha=9, \quad \alpha+=9.99$ \\
\hline
\end{tabular}

Table 3: Range of weights of introduced variables with their respective codes

\section{Variables and their respective codes}

\begin{tabular}{|c|c|c|c|}
\hline Project's Title & $P_{t}$ & Initiative & $\mathrm{I}_{\mathrm{i}}$ \\
\hline Supervisor's Name & $\mathrm{N}_{\mathrm{s}}$ & Log Book & $\mathrm{L}_{\mathrm{b}}$ \\
\hline Section's Number & $\mathrm{S}_{\mathrm{n}}$ & Attendance and Attitude & $\mathrm{A}_{\mathrm{t}} \& \mathrm{~A}_{\mathrm{d}}$ \\
\hline University id's & $\mathrm{U}_{\mathrm{id}}$ & Thesis & $\mathrm{T}_{\mathrm{h}}$ \\
\hline Student's Name & $\mathrm{N}_{\mathrm{s}}$ & Work & $\mathrm{W}_{\mathrm{r}}$ \\
\hline Examiners & $\mathrm{E}_{\mathrm{s}}$ & Presentation and Structure & $\mathrm{P}_{\mathrm{r}} \& \mathrm{~S}_{\mathrm{r}}$ \\
\hline Planning & $\mathrm{P}$ & Clarity & $\mathrm{C}_{\mathrm{ty}}$ \\
\hline Poster & $\mathrm{P}_{\mathrm{o}}$ & Project Demonstration & $P_{d}$ \\
\hline Preparation & $\mathrm{P}_{\mathrm{rn}}$ & Presentation & $\mathrm{P}_{\mathrm{r}}$ \\
\hline
\end{tabular}

Sub Criterias of $P$,

Po , Rp , Ex, Th, Pd, Range of weights Pr and Df

\begin{tabular}{|l|l|}
\hline $\mathrm{P}, \mathrm{P}_{\mathrm{o}}, \mathrm{R}_{\mathrm{p}}$, and $\mathrm{E}_{\mathrm{x}}$ & 0 to $\Phi_{1}$ \\
\hline $\mathrm{T}_{\mathrm{h}}\left(\mathrm{W}_{\mathrm{r}}, \mathrm{C}_{\mathrm{ty}}\right)$ & 0 to $\Phi_{2}$ \\
\hline $\mathrm{P}_{\mathrm{d}}, \mathrm{P}_{\mathrm{r}}$ and $\mathrm{D}_{\mathrm{f}}$ & 0 to $\Phi_{3}$ \\
\hline
\end{tabular}




\begin{tabular}{|l|l|l|l|l|l|}
\hline Presentation \& Defense & $\mathrm{P}_{\mathrm{r}} \& \mathrm{D}_{\mathrm{f}}$ & Defense & \multirow{2}{*}{$\mathrm{D}_{\mathrm{f}}$} & & \\
\cline { 1 - 4 } Progress Report & $\mathrm{R}_{\mathrm{p}}$ & Marks (Out of 100) & $\mathrm{M}_{\mathrm{o} \_} 100$ & & \multirow{2}{*}{$\mathrm{T}_{\mathrm{h}}\left(\mathrm{P}_{\mathrm{r}}^{\&} \mathrm{~S}_{\mathrm{r}}\right)$} \\
\cline { 1 - 4 } Presentation and structure & $\mathrm{P}_{\mathrm{r}} \& \mathrm{~S}_{\mathrm{r}}$ & Weight Sum & $\mathrm{S}_{\mathrm{w}}$ & & \\
\cline { 1 - 4 } & $\mathrm{E}_{\mathrm{x}}$ & Marks Obtained (100) & $\mathrm{M}_{\mathrm{o}}$ & & \\
\hline
\end{tabular}

Sum of Weight Cods $=\sum_{i=1}^{n\left[1,2, m_{14} 14\right)} W i$

Where "W" and " $n$ " is the weight code of different sub criteria's and their respective numeric numbers.

The overall performance of the individual students of a group would be measured by the supervisor through the different scales of mathematical codes, i.e. $\lambda, \lambda+\delta, \delta+\ldots \ldots+$ with its respective numerical value " $\mathrm{N}_{\mathrm{v}}$ ", performance level of individual student with assigned Numeric value $\left(\mathrm{N}_{\mathrm{v}}\right)$ would be measured with certain formulas.

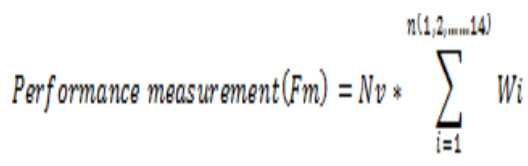

Equation (3) represent the overall performance of individual ones of a particular group is to be measured through the marks awarded by the examiners in respect of numeric value " $\mathrm{N}_{\mathrm{v}}$ " that have been introduced in table 2 and assessment criteria and sub criteria with their respective numeric weights in table 1.

\subsection{The Project}

The focus of this project is to explore how to measure quality of Project in undergraduate education, recognizing the fact that the concept of quality, may mean same scale for the different groups of individual students as well as the project is proposing a Project Quality Assessment Methodology (PQAM) Model, it is multidimensional approach, means how we measure quality of individual one of respective groups in undergraduate education. This project proposes to adapt A Balanced Scorecard(BSC) Approach for measuring quality in graduate education have been developed by Kaplan and Norton in 1992, this project proposes to adapt the BSC approach in measuring quality of project and effort of individual candidates in undergraduate education by applying Project Quality Assessment Methodology(PQAM)Model.

The goal of PQAM Model was to reward an individual student with their respective work to measure the quality in undergraduate education. In this competitive environment there are numbers of approaches applying to measure the quality of project of undergraduate Education, The approach we have taken in this project is to explore briefly how quality has been defined in Undergraduate education. Measuring quality of project in undergraduate education has not fully differentiated the level and performance of work done of individual candidates in different scales. Finally, it was observed that the level of input by students is measuring quality in undergraduate education that is relatively minimal, In our application of the PQAM Model, to measuring the quality of project in undergraduate education, I am proposing the following perspectives; Planning, Poster, Progress Report, Execution, Thesis, Project Demonstration, Presentation and Defense. These eight perspectives were selected and given to the external examiner to measure the performance and award the marks in respect of Weight with its respective weight code. The final perspective in measuring quality of project in undergraduate education is the satisfaction level of students and graduates of the programs.

\section{MEASURING PROJECT QUALITY IN UNDERGRADUATE LEVEL OF EDUCATION}

In developing the quality of project and Performance of students, I suggested some criteria's of project quality improvement related to undergraduate level of education, as described below.

\subsection{Planning}

Fields that are essential to every member of a particular project to understand and complete their module and relates with other members modules.

\subsection{Poster}

Poster is one of the important part of undergraduate project because poster is not a paper; it is more like a billboard. Examiners have approximately one to one-and-a-half minutes to get the idea of your project. It should not look like a burden over the examiners with data, rather, leave them with the concept of your project. Some pieces of information's are very important these should be included in poster like name of the candidates, title of the project, objectives of the project that means why did you choose this project? And list no more than three, Methods should be clear means how did you go about the project?, key points, results or information about your topic, graphs, pictures and at the end of the poster, it is important to write the conclusions means why did you learn or what would you recommend for your topic? 


\subsection{Progress Report}

In project progress report the important to include these information's, Background of project, project goals, project approach, project progress, future work and should be no longer than 12 pages. In addition, you should indicate percent complete for the project. The supporting detail must be representative of the project's percent complete.

\subsection{Execution}

After development of project-group leader will plan and set their appropriate project baselines, it's time to get to work and start executing their project plan. This is often the phase when group member gets more engaged and excited to see things being produced.

\subsubsection{Preparing to Begin the Project Work Involves}

\section{the Following Tasks}

Assigning the project roles to different members(Confirm the individuals who'll perform the project work), Giving and explaining tasks to all team members(Describe to all team members what work they're responsible for producing and how the team members will coordinate their efforts), Defining how the team will perform its essential functions(Decide how the team will handle routine communications, make different project decisions, and resolve conflicts), Setting up necessary tracking systems(Decide which system(s) and accounts they'll use to track schedules, work effort, and expenditures, and set them up), Announcing the project to the Supervisor(Let the project examiners know that your project exists, what it will produce, and when it will begin and end).

\subsubsection{Finally, they get to Perform the Project Work!}

\section{The Performing Group of the Executing Processes}

\section{includes the Following Tasks}

- Doing the tasks: Perform the work that's in your plan.

- Assuring quality: Continually confirm that work and results conform to requirements and applicable standards and guidelines.

- Managing the team: Assign tasks, review results, and resolve problems.

- Developing the team: Provide needed training and mentoring to improve team members' skills.

- Sharing information: Distribute information to appropriate project audiences.

\subsection{Thesis}

The effectiveness of the proposal will depend on the ability to explain the nature, context and scope of the project. Proposals are informative and persuasive writing because they attempt to educate the reader and to convince that reader to do something, The goal of the writer is not only to persuade the reader to do what is being requested, but also to make the reader believe that the solution is practical and appropriate. In persuasive proposal writing, the case is built by the demonstration of logic and reason in the approach taken in the solution, and it should consist of the following information's (i) clear statement of research questions (Be sure that this is understandable to someone who doesn't know much about your field of study), (ii)Project Goal and Objectives (Both the terms imply the target that one's efforts is desired to accomplish: Goals are generically for an achievement or accomplishment for which certain efforts are put, Goals are the vision of the project and Objectives are specifically for targets within the general goal, Objectives are time related to achieve a certain task, Objectives are measurable activities to achieve goals), these two are very important, actually the most important part of your proposal and The rest of the proposal supports these statements(Background/Statement of the Problem/Significance of the Project, Experimental/Project Design, Project timeline, Anticipated results/Final Products and Dissemination, Student's personal statement and Project References).

\subsection{Project Demonstration}

It provides comfort ability to the Supervisor and examiners to see how the project was designed and developed to be applied to each activity and actual group work practices were used in the project for each decided modules that justify the work of all the members of respective group.

\subsection{Presentation}

Before going to present, every group members should be very much familiar and confident over their respective work and it is not important to explain each paper you read mainly talk about results that are immediately related to what you did, Present specific aspect that show the "meat" of your work, Leave the rest out. If you were convincing they will read your paper, don't fill up your slides with lots of equations, Prepare back-up slides to answer questions. Leave them at the end of the presentation Prepare back-up slides to answer questions. Leave them at the end of the presentation and you should keep important points in your mind and these are - expert of respective field will be there, we have to leave them with the thoughts of understood what the problem was and why it was important, what their solution was and how it was different/better than others and the important to impress them at the beginning of talk with easy to understand examples, Spoil the punch line - State your results early and in simple terms because it is an weapon to Motivate your work, Illustrate the basic intuition, Show your solution in action and highlight extreme cases or shortcomings, Show one point at a time it Will help them concentrate on what you are saying, will prevent them from reading ahead, will help you keep your presentation focused, Use decent, standard font like Times New Roman or Arial in different size for main points and secondary points, always be consistent with the background that you use and avoid that are distracting or difficult to read from, Visuals Illustrate your idea with images and diagrams and if you are running out of time cut the general case not the example. 


\subsection{Defense}

It is one of the most challenging phase because you have to defend and justify you work in just 15-20 short minutes in between thesis committee members where none of them actually read your entire thesis, so your answer should be concise, clear, complete, and highlights the originality and novelty of your work.

Table 4: Individual-assessment (IA) of Group-Evaluation (GE) Results from Table 1 \& 2

\begin{tabular}{|c|c|c|c|c|c|c|c|c|c|c|c|c|c|c|c|c|c|c|c|c|}
\hline \multirow{3}{*}{$\mathbf{P}$} & \multirow[b]{3}{*}{$\begin{array}{l}\mathbf{N} \\
\mathbf{s}\end{array}$} & \multirow[b]{3}{*}{$\begin{array}{l}\mathbf{S} \\
\mathbf{n}\end{array}$} & \multirow[b]{3}{*}{$\mathbf{U}_{\mathbf{i d}}$} & \multirow[b]{3}{*}{$\mathbf{N}_{\mathbf{s}}$} & \multirow[b]{3}{*}{$\mathbf{E}_{\mathrm{s}}$} & & \multirow{2}{*}{\multicolumn{2}{|c|}{$\mathbf{P}_{\mathbf{o}}$}} & & \multirow{2}{*}{\multicolumn{3}{|c|}{$\mathbf{E}_{\mathbf{x}}$}} & \multirow{2}{*}{\multicolumn{3}{|c|}{$\mathbf{T}_{\mathbf{h}}$}} & \multirow[b]{3}{*}{$\mathbf{P}_{\mathrm{d}}$} & \multirow[b]{3}{*}{$\mathbf{P}_{\mathbf{r}}$} & \multirow[b]{3}{*}{$\mathbf{D}_{\mathrm{f}}$} & \multirow{3}{*}{$\begin{array}{l}M_{o_{-} 100}= \\
S_{w}\end{array}$} & \multirow[b]{3}{*}{$\begin{array}{l}M_{\mathbf{o}_{-}} \\
100\end{array}$} \\
\hline & & & & & & \multirow[b]{2}{*}{$\mathbf{P}$} & & & \multirow{2}{*}{$\begin{array}{l}R_{p} \\
P_{\mathbf{r}} \\
S_{r} \\
\end{array}$} & & & & & & & & & & & \\
\hline & & & & & & & $\begin{array}{l}\mathbf{P}_{\mathbf{r}} \\
\mathbf{n}\end{array}$ & $\begin{array}{l}\mathbf{P}_{\mathbf{r}} \\
\mathbf{D}_{\mathrm{f}}\end{array}$ & & $\mathbf{I}_{\mathbf{i}}$ & $\mathbf{L}_{\mathbf{b}}$ & $\begin{array}{l}\mathbf{A}_{\mathrm{t}} \\
\boldsymbol{\mathbf { A } _ { \mathrm { d } }} \\
\end{array}$ & $\begin{array}{l}\mathbf{W} \\
\mathbf{r}\end{array}$ & $\begin{array}{l}\mathbf{P}_{\mathbf{r}} \\
\mathbf{S}_{\mathbf{r}}\end{array}$ & $\begin{array}{l}C_{t} \\
y\end{array}$ & & & & & \\
\hline \multirow{4}{*}{$x$} & \multirow{4}{*}{$y$} & \multirow{4}{*}{$z$} & $\begin{array}{l}\mathrm{U}_{\mathrm{id}_{-}} \\
1\end{array}$ & $\begin{array}{l}\mathrm{N}_{\mathrm{s}_{-}} \\
1\end{array}$ & $\begin{array}{l}\mathrm{E}_{\mathrm{s} 1 \text { to }} \\
\mathrm{m}\end{array}$ & $\begin{array}{l}0 \\
\text { to } \\
\Phi_{1} \\
\end{array}$ & $\begin{array}{l}0 \\
\text { to } \\
\Phi_{1} \\
\end{array}$ & $\begin{array}{l}0 \\
\text { to } \\
\Phi_{1} \\
\end{array}$ & $\begin{array}{l}0 \\
\text { to } \\
\Phi_{1} \\
\end{array}$ & $\begin{array}{l}0 \\
\text { to } \\
\Phi_{1} \\
\end{array}$ & $\begin{array}{l}0 \\
\text { to } \\
\Phi_{1} \\
\end{array}$ & $\begin{array}{l}0 \\
\text { to } \\
\Phi_{3} \\
\end{array}$ & $\begin{array}{l}0 \\
\text { to } \\
\Phi_{2} \\
\end{array}$ & $\begin{array}{l}0 \\
\text { to } \\
\Phi_{4} \\
\end{array}$ & $\begin{array}{l}0 \\
\text { to } \\
\Phi_{2} \\
\end{array}$ & $\begin{array}{l}0 \\
\text { to } \\
\Phi_{3}\end{array}$ & $\begin{array}{l}0 \\
\text { to } \\
\Phi_{3} \\
\end{array}$ & $\begin{array}{ll}0 & \text { to } \\
\Phi_{3}\end{array}$ & $\mathrm{~S}_{\mathrm{w}_{-} 1}$ & $\mathrm{M}_{\mathrm{o} 1}$ \\
\hline & & & $\mathrm{U}_{2}$ & $\begin{array}{l}\mathrm{N}_{\mathrm{s}_{-}} \\
2\end{array}$ & $\begin{array}{l}\mathrm{E}_{\mathrm{s} 1 \text { to }} \\
\mathrm{m}\end{array}$ & $\begin{array}{l}0 \\
\text { to } \\
\Phi_{1} \\
\end{array}$ & $\begin{array}{l}0 \\
\text { to } \\
\Phi_{1} \\
\end{array}$ & $\begin{array}{l}0 \\
\text { to } \\
\Phi_{1} \\
\end{array}$ & $\begin{array}{l}0 \\
\text { to } \\
\Phi_{1} \\
\end{array}$ & $\begin{array}{l}0 \\
\text { to } \\
\Phi_{1} \\
\end{array}$ & $\begin{array}{l}0 \\
\text { to } \\
\Phi_{1} \\
\end{array}$ & $\begin{array}{l}0 \\
\text { to } \\
\Phi_{3} \\
\end{array}$ & $\begin{array}{l}0 \\
\text { to } \\
\Phi_{2} \\
\end{array}$ & $\begin{array}{l}0 \\
\text { to } \\
\Phi_{4} \\
\end{array}$ & $\begin{array}{l}0 \\
\text { to } \\
\Phi_{2} \\
\end{array}$ & $\begin{array}{l}0 \\
\text { to } \\
\Phi_{3} \\
\end{array}$ & $\begin{array}{l}0 \\
\text { to } \\
\Phi_{3} \\
\end{array}$ & $\begin{array}{ll}0 & \text { to } \\
\Phi_{3}\end{array}$ & $\mathrm{~S}_{\mathrm{w} \_2}$ & $\mathrm{M}_{\mathrm{o} 2}$ \\
\hline & & & $\ldots$ & $\cdots$ & $\begin{array}{l}\mathrm{E}_{\mathrm{s} 1 \text { to }} \\
\mathrm{m}\end{array}$ & $\begin{array}{l}0 \\
\text { to } \\
\Phi_{1}\end{array}$ & $\begin{array}{l}0 \\
\text { to } \\
\Phi_{1}\end{array}$ & $\begin{array}{l}0 \\
\text { to } \\
\Phi_{1}\end{array}$ & $\begin{array}{l}0 \\
\text { to } \\
\Phi_{1}\end{array}$ & $\begin{array}{l}0 \\
\text { to } \\
\Phi_{1}\end{array}$ & $\begin{array}{l}0 \\
\text { to } \\
\Phi_{1} \\
\end{array}$ & $\begin{array}{l}0 \\
\text { to } \\
\Phi_{3} \\
\end{array}$ & $\begin{array}{l}0 \\
\text { to } \\
\Phi_{2}\end{array}$ & $\begin{array}{l}0 \\
\text { to } \\
\Phi_{4}\end{array}$ & $\begin{array}{l}0 \\
\text { to } \\
\Phi_{2} \\
\end{array}$ & $\begin{array}{l}0 \\
\text { to } \\
\Phi_{3}\end{array}$ & $\begin{array}{l}0 \\
\text { to } \\
\Phi_{3}\end{array}$ & $\begin{array}{ll}0 & \text { to } \\
\Phi_{3}\end{array}$ & $\cdots$ & .. \\
\hline & & & $\mathrm{U}_{\mathrm{n}}$ & $\begin{array}{l}\mathrm{N}_{\mathrm{s}_{-}} \\
\mathrm{n}\end{array}$ & $\begin{array}{l}\mathrm{E}_{\mathrm{s} 1 \text { to }} \\
\mathrm{m}\end{array}$ & $\begin{array}{l}0 \\
\text { to } \\
\Phi_{1} \\
\end{array}$ & $\begin{array}{l}0 \\
\text { to } \\
\Phi_{1} \\
\end{array}$ & $\begin{array}{l}0 \\
\text { to } \\
\Phi_{1}\end{array}$ & $\begin{array}{l}0 \\
\text { to } \\
\Phi_{1} \\
\end{array}$ & $\begin{array}{l}0 \\
\text { to } \\
\Phi_{1} \\
\end{array}$ & $\begin{array}{l}0 \\
\text { to } \\
\Phi_{1} \\
\end{array}$ & $\begin{array}{l}0 \\
\text { to } \\
\Phi_{3} \\
\end{array}$ & $\begin{array}{l}0 \\
\text { to } \\
\Phi_{2} \\
\end{array}$ & $\begin{array}{l}0 \\
\text { to } \\
\Phi_{4} \\
\end{array}$ & $\begin{array}{l}0 \\
\text { to } \\
\Phi_{2} \\
\end{array}$ & $\begin{array}{l}0 \\
\text { to } \\
\Phi_{3} \\
\end{array}$ & $\begin{array}{l}0 \\
\text { to } \\
\Phi_{3} \\
\end{array}$ & $\begin{array}{ll}0 & \text { to } \\
\Phi_{3}\end{array}$ & $S_{w_{-} n}$ & $\mathrm{M}_{\mathrm{on}}$ \\
\hline
\end{tabular}

All the variables have already defined in Table 3 and their respective weight in Table 1 , where " $n$ " is the number of students and " $\mathrm{m}$ " is the number of examiners for respective groups.

Table 5: Individual-assessment (IA) of Group-Evaluation (GE) Results based on Table 4

\begin{tabular}{|l|l|l|l|}
\hline $\mathrm{M}_{\mathrm{o} 1}=$ & $\mathrm{M}_{\mathrm{o} 2}=$ & $\ldots$ & $\mathrm{M}_{\mathrm{on}}=\left(\mathrm{S}_{\mathrm{w} \_\mathrm{n}}\right) / \mathrm{m}$ \\
\hline
\end{tabular}

\section{TRUSTWORTHINESS}

To address notions of trustworthiness of the data presented in this study, four criteria's of Guba's (1. credibility, 2. transferability, 3. dependability \& 4. confirm- ability) have been considered with additional strategies suggested by Shenton. Comparison between the students' conceptions of fair assessment. 'F. Javier Murillo [2], the introduced methodology of trustworthiness of the data presented in nine criteria's (1. Planning, 2. Poster, 3. Progress Report, 4. Execution, 5. Thesis, 6.Project Demonstration, 7. Presentation and 8.Defence). The introduced variable in this study is the method of evaluations of individual learning as well as collaborative learning, the academic task was first explained to the students in both the respect individual and collaborative learning with their respective criteria's and marks weightage, so this way of learning encourage the students to discuss 'why' and 'how' to proceed their work to reach up to their goals and achieve respective weightage, Supervisor are in more interaction with a group members, to make a trust over the group members a fair assessment besides valuing the grades should also assess the ability of being together with each other, Examiners judge their individual and collaborative performance based on their live performance where students just have to memorize and they really don't think that is useful because after two weeks they forget everything. So besides an exam, Supervisor have to take into account some data based on introduced criteria's that have to use other tests to know each other better and how students learn. These tests may be individual assignments where we discuss or reflect on some important issue because after all what they learn is all related and they are the group members in one project. As per the output of students in measuring quality of undergraduate education has been relatively Minimal. The different criteria's can be used for continuous improvement and as part of the marks rewarding at performance levels. It is on the basis of this theoretical framework, we developed the concepts to measure Project Quality for undergraduate Level. As indicated, the performance of students output in measuring performance and quality.

We have selected important criteria to make a case for a multidimensional approach to measuring quality of project in undergraduate education. Assuming the standard criteria of the approach, one should not expect an improvement in overall project quality, if only few members of the specific project are being rewarded. At the end, Supervisor and Examiners must use an equation that considers all the relevant variables. For example if a student is rewarded basis of overall performance, it stands to reason for those students to focus their efforts on increasing performance. However, if reward is on the basis of multiple criteria then we expect those students to respond accordingly. As depicted in Figure above, the importance of and thus weight allocated to each of the seven perspectives on project quality. 
Table 6: Measuring Project quality and individual performance as per different criteria also implies the opportunity for continuous improvement, Comparison between the students' conceptions of fair assessment. ' $F$. Javier Murillo' 2017

\begin{tabular}{|c|c|}
\hline \multicolumn{2}{|c|}{$\begin{array}{l}\text { Comparison between the students' conceptions of fair } \\
\text { assessment. }\end{array}$} \\
\hline $\begin{array}{l}\text { Egalitarian } \\
\text { Assessment }\end{array}$ & Equitable Fair assessment \\
\hline $\begin{array}{l}\text { Making criteria explicit } \\
\text { Objectivity } \\
\text { Transparency and } \\
\text { explicitness of the criteria } \\
\text { Performance } \\
\text { Examination as a key } \\
\text { element of assessment } \\
\text { Use of qualitative tests only } \\
\text { as a complement of exams } \\
\text { Assessment of class contents } \\
\text { Equal assessment for all } \\
\text { students }\end{array}$ & $\begin{array}{l}\text { Adapting the criteria to the } \\
\text { needs of each student } \\
\text { Subjectivity in favor of each } \\
\text { student } \\
\text { Individualized assessment } \\
\text { criteria } \\
\text { Progress and effort } \\
\text { Reducing the weight of the } \\
\text { exam in the assessment } \\
\text { Use of qualitative tests in the } \\
\text { assessment } \\
\text { Assessment of attitudes and } \\
\text { values } \\
\text { Assessment adapted to each } \\
\text { student }\end{array}$ \\
\hline
\end{tabular}

\subsection{Data Analysis}

As describe earlier the proposed PQAM Model will give differences to different level of project and their respective member with their performance in modules. Understanding that different projects have different missions and strategic focus, the proposed approach suggests that the different perspectives as shown in the diagram above should be given different weights.

Different Examiners for the same group of project may assign weights differently to every candidates depending upon the live performance and the feedback given by the respective supervisor as per the evaluation based on different criteria and sub criteria's.

The weight distributions among the different criteria's should be consistent with the work and performance of individual ones. The distribution of weights can be proposed by Supervisor and be approved by the Examiners of Project committees with final approval by the Head of the Committee.

Table 7: Performance based result evaluation of different sections

\begin{tabular}{|c|c|c|c|c|c|c|c|c|c|c|c|c|c|}
\hline Grade Range & Codes & Grades => & & & & & $\mathbf{A}$ & B & $\mathrm{C}$ & D & $\mathbf{F}$ & $\begin{array}{l}\text { Pass } \\
\%\end{array}$ & Fail \% \\
\hline $90 \leq\left(\mathrm{M}_{\mathrm{o}_{-}} 100\right) \leq 100$ & $\mathrm{R}_{1}$ & Range $=>$ & & & & & $R_{1}$ & $R_{2}$ & $R_{3}$ & $R_{4}$ & $R_{5}$ & $\boldsymbol{R}_{6}$ & $\boldsymbol{R}_{7}$ \\
\hline $80 \leq\left(\mathrm{M}_{\mathrm{o}_{-}} 100\right) \leq 89$ & $\mathrm{R}_{2}$ & \multirow{6}{*}{$\begin{array}{l}\text { Total no. of Students of } \\
\text { individual Section }=>\end{array}$} & \multirow{2}{*}{$n=3$} & \multirow{2}{*}{$\mathrm{P}_{\mathrm{t}}=\mathrm{x}_{1}$} & \multirow{2}{*}{$\mathrm{N}_{\mathrm{s}}=\mathrm{y}_{1}$} & \multirow{2}{*}{$S_{n}=z_{1}$} & \multirow{2}{*}{1} & \multirow{2}{*}{1} & \multirow{2}{*}{1} & \multirow{2}{*}{0} & \multirow{2}{*}{0} & \multirow{2}{*}{$100 \%$} & \multirow{2}{*}{$0 \%$} \\
\hline $70 \leq\left(\mathrm{M}_{\mathrm{o}_{-}} 100\right) \leq 79$ & $\mathrm{R}_{3}$ & & & & & & & & & & & & \\
\hline $60 \leq\left(\mathrm{M}_{\mathrm{o}_{-}} 100\right) \leq 69$ & $\mathrm{R}_{4}$ & & \multirow{2}{*}{$n=4$} & \multirow{2}{*}{$P_{t}=x_{2}$} & \multirow{2}{*}{$\mathrm{N}_{\mathrm{s}}=\mathrm{y}_{2}$} & \multirow{2}{*}{$S_{n}=z_{2}$} & \multirow{2}{*}{1} & \multirow{2}{*}{2} & \multirow{2}{*}{0} & \multirow{2}{*}{0} & \multirow{2}{*}{1} & \multirow{2}{*}{$75 \%$} & \multirow{2}{*}{$25 \%$} \\
\hline $0 \leq\left(\mathrm{M}_{\mathrm{o}_{-}} 100\right) \leq 59$ & $\mathrm{R}_{5}$ & & & & & & & & & & & & \\
\hline $60 \leq\left(\mathrm{M}_{\mathrm{o}_{-}} 100\right) \leq 100$ & $\mathrm{R}_{6}$ & & \multirow{2}{*}{$n=3$} & \multirow{2}{*}{$P_{t}=x_{3}$} & \multirow{2}{*}{$\mathrm{N}_{\mathrm{s}}=\mathrm{y}_{3}$} & \multirow{2}{*}{$S_{n}=z_{3}$} & \multirow{2}{*}{0} & \multirow{2}{*}{0} & \multirow{2}{*}{0} & \multirow{2}{*}{0} & \multirow[b]{2}{*}{3} & \multirow{2}{*}{$0.00 \%$} & \multirow{2}{*}{$100 \%$} \\
\hline $0 \leq($ Mo_100) $\leq 59$ & $\mathrm{R}_{7}$ & & & & & & & & & & & & \\
\hline
\end{tabular}

Performance based result is to be evaluated, Pass $\%=100$ $((\mathrm{F} / \mathrm{n}) * 100)$ find out the result based analysis of different sections with their respective number of students, grade codes have been assigned as per the ranges of achieved marks of individual member of respective groups that have been shown in table 7 and based on pass percentage, fail percentage is to be evaluated and it has been coded with grade range code $R_{7}$ to evaluate pass percentage of respective sections.

Table 8: Graphical representation based on result evaluation of different sections (Fig. 1 to Fig. 3)
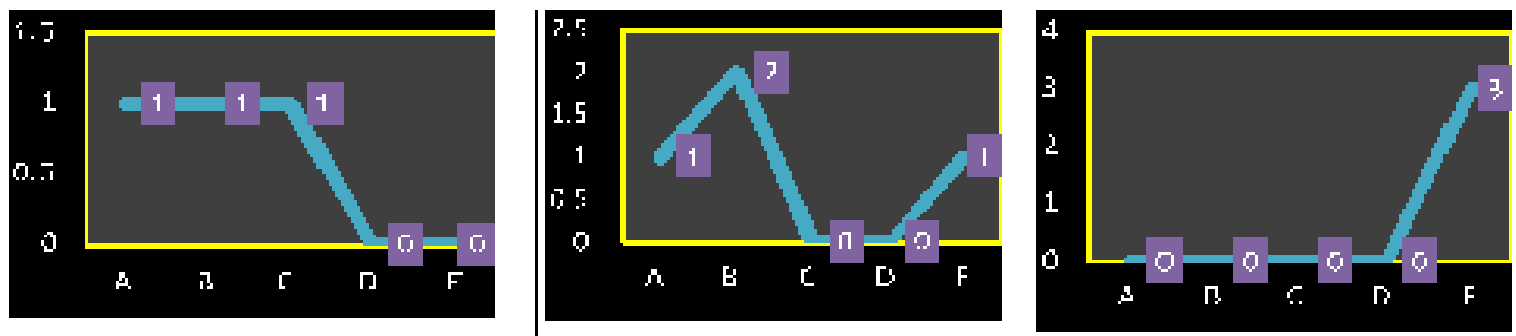
The above graphs (Fig. 1, Fig. 2 and Fig. 3) of table 8, shows the graphical representation, based on result evaluation of different sections that have been introduced in Table 7 , in figure 1 , there are three students have been introduced with their respective grades A, B and C, similarly in figure 2, there are four students with grades $\mathrm{A}, \mathrm{B}$ and $\mathrm{F}$, Here 1 in grade $A, 2$ in grade $B$ and 1 in grade $F$ and similarly in figure 3, all three students are under grade F.

\section{Weightage}

Weightage of project is to be measured based on the performance of Group as well as individual ones and it shows their seriousness, if the weightage of section is low or high that shows their efforts and dedication over the work, to improve the performance of a group it is important for them to follow the regular instructions given by supervisor based on the scale of decided criteria's, it will improve their confident with the process to evaluate their performance based on self-assessment criteria's to increase the weightage of assessment, This study is also based on the use of the logs and the wiki for the supervisor of respective groups to check their individual performance based on regular assessment, it provides an extra data source on who was doing what and when, meaning the supervisor was able to intervene when groups were falling behind, or when some group members were not contributing.

\section{Monitoring}

Regular monitoring during the study through the supervisor based on introduced scale to measure the performance of individual students in a group to justify their grade based on who and what was being contributed. First, results from the self-assessment and group-evaluation produced valuable data on the group process in terms of feedback from individual group members. Secondly, through the Wiki logs, the supervisor could monitor who was regular to improve work performance and updating information's as per supervisor guidelines. This does not provide conclusive evidence of contribution, though it does supply the supervisor with more information on the group process, which could be used for grading purposes. This finding is substantiated by Caple and Bogle, who also discovered that wiki logs could help to make group work grading fairer. Wikis were a valuable tool in this study, as they allowed the supervisor to be a silent partner in the group process.

\section{CONCLUSION}

In this paper, the concept have been introduced to justify the works and effort of individual one in specific group of the project, introduced two questions will support to the examiners as well as to supervisor to justify the awarded marks or grade of every one based on different introduced criteria's, at the end of the approach, to use all criteria's for all the members of respective groups to get relevant information for assigning individual grades. A supervisor assessment was carried out for each student to assess the performance such as collaboration, research, participation, and provide each with an individual score. Then, the final project work was assessed entirely by the supervisor and examiners to award a group score. The individual awarded score from the Supervisor and the examiners where combined to produce an individual grade for each group members. To use this approach to justify a group-evaluation, which asked each examiners to state who had worked hard, and who needed to work harder. Aside from this, the supervisor also use wikis in order to become a silent partner in the group progress by monitoring contribution through the wiki logs. The work in a group is a complex, as it requires a number of members collaborating together in order to produce a piece of work. The introduced process can be made more effective and less stressful by creating a transparent assessment system for the students to analyze how they think they should be assessed. Not only does this provide a fairer system of grading, it also allows the learners to become more aware of the assessment process and what is actually expected of them.

\section{REFERENCES}

[1] Simon Williams, "Investigating the allocation and corroboration of individual grades for project-based learning" Science Direct, Elsevier, Volume 53, pp. 19, June 2017.

[2] F. Javier Murillo and Nina Hidalgo, "Students' conceptions about a fair assessment of their learning" Science Direct, Elsevier, Volume 53, pp. 10-16, June 2017.

[3] Dr Kate Exley, "Managing and Assessing Students Working in Groups" Queen's University, Belfast, May 2010.

[4] Bryan W. Griffin, "Perceived autonomy support, intrinsic motivation, and student ratings of instruction" Science Direct, Elsevier, Volume 51, pp. 116-125, December 2016.

[5] SALLY BROWN, "Assessment for Learning" Learning and Teaching in Higher Education, Issue 1, 2004-05.

[6] Ian Jones and Chris Wheadon, "Peer assessment using comparative and absolute judgement" Science Direct, Elsevier, Volume 47, pp. 93-101, December 2015.

[7] Stavroula Valiandes, "Evaluating the impact of differentiated instruction on literacy and reading in mixed ability classrooms: Quality and equity dimensions of education effectiveness" Science Direct, Elsevier, Volume 45, pp. 17-26, June 2015.

[8] Heidi Hyytinen, Kari Nissinen, Jani Ursin , Auli Toom , and Sari Lindblom-Yla"nne, "Problema tising the equivalence of the test results of performancebased critical thinking tests for undergraduate students" Science Direct, Elsevier, Volume 44, pp. 18, March 2015.

[9] Emily R. Lai, "Collaboration: A Literature Review" Always Learning, Pearson, June 2011

[10] Antonella Certa, Mario Enea and Fabrizio Hopps, “A multi-criteria approach for the group assessment of an academic course: A case study" Science Direct, Elsevier, Volume 44, pp. 16-22, March 2015.

[11] Robbert Smit and Thomas Birri, "Assuring the quality of standards-oriented classroom assessment with rubrics for complex competencies" Science 
Direct, Elsevier, Volume 43, pp. 5-13, December 2014.

[12] Phil Race, "A Briefing on Self, Peer and Group Assessment" LTSN Generic CentreA Briefing on Self, Peer and Group Assessment, November 2001

[13] Hien M. VO, Chang Zhu and Nguyet A. Diep, "The effect of blended learning on student performance at course-level in higher education: A meta-analysis" Science Direct, Elsevier, Volume 53, pp. 17-28, February 2017.

[14] Wouter Schelfhout, Kristien Bruggeman and Sven De Maeyer, "Evaluation of entrepreneurial competence through scaled behavioural indicators: Validation of an instrument" Science Direct, Elsevier, Volume 51, pp. 29-41, September 2016.

[15] Gibbs, G. "The Assessment of group work: Lessons from the literature" The University of Queensland Australia, March 2012.

[16] Dorien Hopster-den Ottera, Saskia Wools, Theo J.H.M. Eggen and Bernard P. Veldkamp, "Formative use of test results: A user's perspective" Science Direct, Elsevier, Volume 52, pp. 12-23, November 2016.

[17] Georgia Solomonidou and Michalis Michaelides, 'Students' conceptions of assessment purposes in a low stakes secondary-school context: A mixed methodology approach" Science Direct, Elsevier, Volume 52, pp. 35-41, December 2016.

[18] Kathayoon A. Khalil, Nicole M. Ardoinb and Deborah J. Wojcik, "The company you keep: Networks in a community of informal education evaluators" Science Direct, Elsevier, Volume 51, pp. 7-16, August 2016.

[19] ROBERT E. SLAVIN, "Research on Cooperative Learning and Achievement: What We Know, What We Need to Know" CONTEMPORARY EDUCATIONAL PSYCHOLOGY 21, 43-69 (1996) ARTICLE NO. 0004.

[20] Rikkert M. van der Lans, Wim J.C.M. van de Grift, Klaas van Veen and Marjon Fokkens-Bruinsma, "Once is not enough: Establishing reliability criteria for feedback and evaluation decisions based on classroom observations" Science Direct, Elsevier, Volume 50, pp. 88-95, August 2016. 